\title{
On your mark: emergency medicine and the Vancouver Olympic Games
}

Trevor S. Langhan, MD

Canadians are known to be humble and often selfdeprecating. Over 17 days during the Vancouver Olympic Games in 2010, we allowed ourselves to feel a sense of worth, to wave the flag, to be proud of being Canadian. Across the country, Canadians celebrated and congratulated each other as the medal count climbed and our athletes broke records, including the record for gold medals. As a volunteer working the Whistler Polyclinic, it felt good, exceptional even, to see our countrymen and -women exceed lofty expectations. Meek no longer, we shouted from the rooftops and announced our presence on an international stage. There was an outcry of patriotism, a swagger. Some thought the swagger was always there and that it simply needed a reason to be set free. ${ }^{1}$ Canada was due.

A CMAF editorial correlated the Olympic movement with health care delivery. ${ }^{2}$ The author espoused the benefits of the pursuit of excellence. In it, Dr. Hebert asserted that adopting the pursuit of excellence should be an ideal in health care, health education, and health research. I agree with Dr. Hebert and encourage all those who practice emergency medicine to continue to strive to exceed expectations.

I would ask something else: that emergency medicine have its own swagger. What Canada was to the international community, emergency medicine is to the medical community. By nature, those who work in the trenches of the emergency department are selfdeprecating and humble. How often have you yourself said or overheard a colleague say, "I'm just an emerg doc." Just?

For too long, we have downplayed the importance of our jobs. There is pride in what we do, but we lack a sense of community. Our accessibility and accountability set the standard for patient care, yet emergency medicine struggles for an identity at a national level. Cynicism is easy. ${ }^{1}$ The challenge is standing up for our beliefs. We must band together for there is power in the collective. We should continue to promote emergency medicine: promote it among ourselves, advocate for its inclusion in medical school curricula, argue for an increase in postgraduate training spots, and lobby for funding at the political level.

The swagger is there. We simply need to set it free. If it took the Olympic Games in Vancouver for Canadians to puff out their chests with pride, what will it take for emergency physicians to do the same? We are due.

Competing interests: None declared.

\section{REFERENCES}

1. CTV. Olympic video essay. Available at: http://www.youtube. $\mathrm{com} /$ watch? $\mathrm{v}=\mathrm{xapbavrcoyk} \&$ feature $=$ related (accessed March 20, 2010).

2. Hebert PC. Why the pursuit of excellence matters. CMAJ 2010;182:121.

From the Foothills Medical Centre, Division Emergency Medicine, University of Calgary, Calgary, AB.

Correspondence to: Dr. Trevor S. Langhan, Foothills Medical Centre, Division of Emergency Medicine, University of Calgary, C231, 1403-29th Street NW, Calgary, AB T2N 2T9; trevorlanghan@me.com.

Submitted April 3, 2010; Revised May 28, 2010; Accepted May 29, 2010.

This article has been peer reviewed.

(c) Canadian Association of Emergency Physicians 